\title{
Clinical Characteristics and Management of Saccular Cysts: A Single Institute Experience
}

\author{
Joo Hyun $\mathrm{Kim}^{1}$ (i) $\cdot$ Myeong Hee Kim${ }^{1} \cdot$ Hong Geun Ahn $\cdot$ Hong-Shik $\mathrm{Choi}^{2} \cdot$ Hyung Kwon Byeon ${ }^{3}$ (i) \\ ${ }^{1}$ Department of Otorhinolaryngology-Head and Neck Surgery, Konyang University College of Medicine, Daejeon; \\ ${ }^{2}$ Department of Otorhinolaryngology, Institute of Logopedics and Phoniatrics, Yonsei University College of Medicine, Seoul; \\ ${ }^{3}$ Department of Otolaryngology-Head and Neck Surgery, Soonchunhyang University Seoul Hospital, Soonchunhyang University College of \\ Medicine, Seoul, Korea
}

Objectives. A saccular cyst is defined as a dilated saccule of the larynx, filled with mucus, and is located between the false vocal cords and the thyroid cartilage. Although this uncommon laryngeal condition is benign in nature, it could lead to dyspnea, stridor, and airway obstruction, depending on its size and location. Furthermore, some saccular cysts have been associated with laryngeal carcinoma. This study aimed to characterize this rather uncommon laryngeal condition to aid in determining the proper management of this pathology.

Methods. Medical records were retrospectively reviewed of all patients with saccular cysts diagnosed and treated between 2006 and 2017 at a tertiary otolaryngologic care center.

Results. Seven patients with saccular cysts were identified (male:female=2:5; mean age, 34.1 years); two were pediatric patients. Surgical intervention was performed in all patients by laryngo-microsurgery using $\mathrm{CO}_{2}$ laser. There was no recurrence after the initial surgical treatment.

Conclusion. Saccular cysts can be managed endoscopically using $\mathrm{CO}_{2}$ laser, without requiring an external approach. Therefore, an endoscopic approach should be actively considered for an optimal treatment outcome.

Keywords. $\mathrm{CO}_{2}$ Laser; Laryngo-Microsurgery; Larynx; Saccule; Saccular Cyst

\section{INTRODUCTION}

A saccular cyst is defined as a dilated saccule of the larynx that is filled with mucus and can be acquired or congenital. It is a benign lesion that is located between the false vocal cords and the thyroid cartilage [1]. The symptoms are related to the patient's age, location, and size of the cyst. Airway compromise is the most common symptom in infants, whereas voice change is more common in adults [1-3]. Although this rather uncommon laryngeal condition is benign in nature, a saccular cyst could

\footnotetext{
- Received June 4, 2018

Revised September 19, 2018

Accepted September 27, 2018

- Corresponding author: Hyung Kwon Byeon

Department of Otolaryngology-Head and Neck Surgery, Soonchunhyang

University Seoul Hospital, Soonchunhyang University College of Medicine,

59 Daesagwan-ro, Yongsan-gu, Seoul 04401, Korea

Tel: +82-2-710-3084, Fax: +82-2-795-3687

E-mail: ewellcastle@gmail.com
}

lead to dyspnea, stridor, and airway obstruction depending on its size and location. Furthermore, there have been reports of saccular cysts associated with laryngeal carcinoma [4-6]. If saccular cysts are diagnosed accurately and treated appropriately at an early point, the morbidity and the possibility of requiring an external approach for surgery could be reduced. However, many otolaryngologists find it difficult to make an accurate diagnosis and an appropriate treatment decision for saccular cysts. Therefore, this study aimed to review patients with saccular cysts to clarify this uncommon laryngeal condition and to aid in determining the proper management of this pathology.

\section{MATERIALS AND METHODS}

\section{Participants}

This study involved seven patients who were admitted and surgically treated for saccular cysts at the Department of Otorhino-

Copyright () 2019 by Korean Society of Otorhinolaryngology-Head and Neck Surgery.

This is an open-access article distributed under the terms of the Creative Commons Attribution Non-Commercial License (http://creativecommons.org/licenses/by-nc/4.0)

which permits unrestricted non-commercial use, distribution, and reproduction in any medium, provided the original work is properly cited. 
laryngology, Gangnam Severance Hospital between April 2006 and December 2017. Written informed consents were obtained from all the patients before the surgery. Approval for this retrospective review study was obtained from the appropriate Institutional Review Board (IRB No. 3-20160073). All patients with other synchronous vocal fold lesions or vocal cord paralysis were excluded. Any patients who were lost to follow up or had incomplete data were also excluded. None of the patients were professional voice users. The impression of a saccular cyst was made based on video laryngeal stroboscopy (Laryngograph Ltd., London, UK) at the outpatient clinic.

\section{Surgical approach}

The lesions were all surgically removed by laryngomicrosurgery under general anaesthesia, which was performed by the senior author (HSC). All patients underwent orotracheal intubation without notable difficulty. The supraglottic cystic lesions were all fully visible via suspension laryngoscopy. Surgical resection was performed endoscopically using $\mathrm{CO}_{2}$ laser. A mucosal incision was made into the superior surface of the cyst using $\mathrm{CO}_{2}$ laser with 1-3 watts power and continuous mode. Next, the cyst wall was dissected with laryngeal microinstruments to separate the surrounding tissue. The cyst was then excised and bleeding was controlled using the $\mathrm{CO}_{2}$ laser (Fig. 1).

\section{Voice analysis and statistical analysis}

Voice analyses were performed in adult patients before and at 3 months after surgery. Voice analysis included aerodynamic measures (phonatory aerodynamic system model 6600; KayPENTAX, Montvale, NJ, USA), acoustic analysis (multi-dimensional voice program model 5105, KayPENTAX), electroglottographic (EGG) analysis (real-time EGG analysis, KayPENTAX), and voice handicap index (VHI). The aerodynamic measures included maximum phonation time, mean flow rate, and subglottic pressure. EGG analysis consisted of mean fundamental frequency, mean closed quotient, percentage irregularity of frequency, and percentage irregularity of amplitude. Acoustic analysis consisted of jitter \%, shimmer \%, and noise-to-harmonic ratio. The VHI evaluated the patient's perception of their own voice. Pre- and postoperative results of each of the voice parameters were statistically compared using SPSS ver. 18.0 (SPSS Inc., Chicago, IL, USA), with statistical significance defined as a $P$-value less than 0.05 . Paired $t$-tests were used for statistical analysis of voice parameters across the two time-points.

\section{H I G H L I G G H T S}

- A saccular cyst is a rare but potentially harmful condition that can lead to airway compromise or malignant transformation.

- Saccular cysts can be mostly managed endoscopically using $\mathrm{CO}_{2}$ laser, without requiring an external approach.

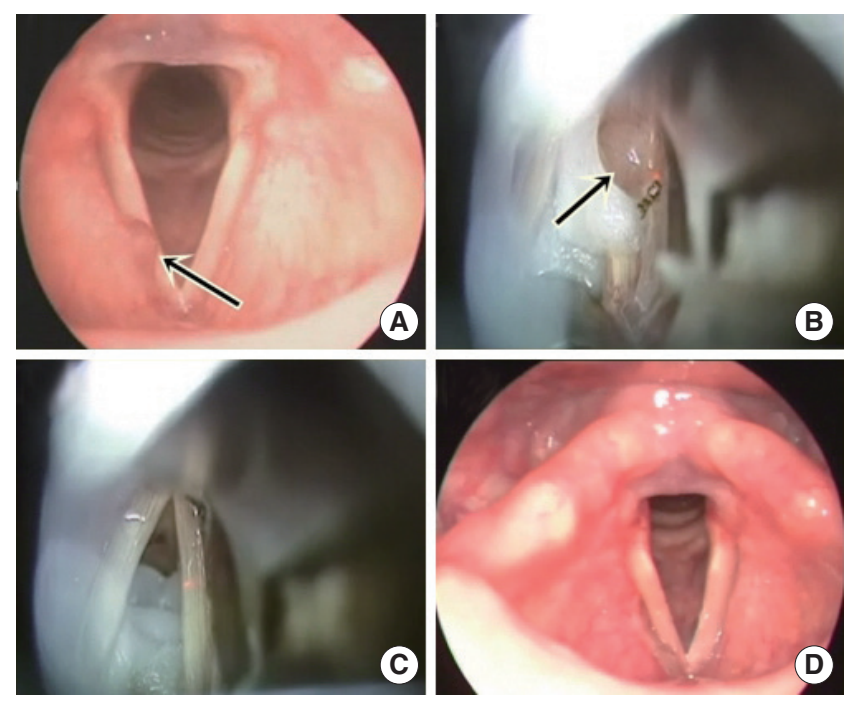

Fig. 1. Initial and postoperative laryngeal-stroboscopic imaging and operative findings of a 58-year-old female patient with saccular cyst. (A) Preoperative laryngeal-stroboscopic image of saccular cyst (arrow) arising from anterior part of right false vocal cord. (B) Intraoperative image showing excision of saccular cyst (arrow) on the right side using $\mathrm{CO}_{2}$ laser ( 3 watts superpulse continuous mode) under suspension laryngoscope. (C) Intraoperative image after complete removal of saccular cyst. (D) Three months postoperative, laryngealstroboscopic image.

\section{RESULTS}

A total of seven cases with saccular cysts were identified by video-laryngeal stroboscopy within the study period. The seven patients included two males and five females with a mean age of 34.1 years (range, 1 to 81 years). Two patients were infants and five patients were adults (mean age of adults, 47.4 years). The two pediatric patients were initially presented to the clinic with stridor and both had a history of premature birth and prior intubation.

One infant was intubated for 10 days due to bronchiolitis and the other infant was intubated for 37 days due to respiratory distress syndrome. The remaining adult patients had no predisposing factors. The patients initially visited the clinic with dysphonia, foreign body sense, and cough. Two patients presented a saccular cyst on the left false vocal cord; two patients had a cyst on the right false vocal cord; and the remaining three patients had bilateral cysts. In all cases, the saccular cysts were in the anterior part of larynx (between true and false vocal folds) as examined by laryngeal stroboscopy. Adjunctive radiographic imaging studies were not performed since all cases were small anterior saccular cysts.

In all cases, the cyst was completely excised under endoscopic resection with $\mathrm{CO}_{2}$ laser without any damage to other uninvolved sites of the larynx such as the true vocal cord. Tracheotomy was not performed in any of the cases. All removed speci- 
mens were pathologically confirmed as saccular cysts lined with respiratory epithelium, with no evidence of underlying malignancy. There was no recurrence of the lesion during the mean follow-up period of 20.6 months (range, 10 to 35 months) in any of the cases. The clinical features of all of the patients are summarized in Table 1 . The results of the voice analyses conducted before and after the operation were compared (Table 2). All parameters showed a general improvement after the endoscopic resection although none of these differences were statistically significant, due to the small number of patients. Also, a systematic review of the reports made on saccular cysts in the current literature was conducted by PubMed search on the basis of keywords and their synonyms relating to saccular cysts with exclusion of case reports (Table 3) [2,7-9]. The search was carried out covering the period up to 2017.

\section{DISCUSSION}

A saccular cyst is a very rare condition of the larynx. Most reports of saccular cysts in the medical literature are based on small groups of patients [2,10]. Not surprisingly, in our study, we identified only seven such cases over a 11-year period. There-
Table 2. Pre- and postoperative voice parameters of patients with saccular cysts $(n=5)$

\begin{tabular}{lccc}
\hline Variable & Preoperative & $\begin{array}{c}\text { 3-Month } \\
\text { postoperative }\end{array}$ & $P$-value \\
\hline Aerodynamic measure & & & \\
MPT (sec) & $13.2 \pm 0.6$ & $13.8 \pm 2.6$ & 0.761 \\
MFR (L/sec) & $0.2 \pm 0.1$ & $0.2 \pm 0.2$ & 0.886 \\
Psub (cmH $\left.{ }_{2} \mathrm{O}\right)$ & $5.7 \pm 2.8$ & $6.6 \pm 0.7$ & 0.761 \\
EGG analysis (\%) & & & \\
CQ & $36.1 \pm 6.5$ & $29.5 \pm 5.2$ & 0.815 \\
CFx & $6.6 \pm 15.9$ & $10.4 \pm 14.8$ & 0.471 \\
CAx & $2.6 \pm 7.0$ & $2.6 \pm 4.3$ & 0.342 \\
Acoustic analysis & & & \\
F0 (Hz) & $150.4 \pm 57.3$ & $161.8 \pm 71.9$ & 0.465 \\
NHR & $0.142 \pm 0.005$ & $0.122 \pm 0.018$ & 0.269 \\
Jitter (\%) & $1.5 \pm 1.4$ & $1.0 \pm 1.0$ & 0.342 \\
Shimmer (\%) & $4.0 \pm 0.1$ & $3.3 \pm 0.3$ & 0.158 \\
Patient-perceived satisfaction & & & \\
VHI score & $51.0 \pm 19.3$ & $37.0 \pm 19.4$ & 0.132 \\
\hline
\end{tabular}

Values are presented as mean \pm standard deviation.

MPT, maximum phonation time; MFR, mean flow rates; Psub, subglottic pressure; $\mathrm{EGG}$, electroglottographic; $\mathrm{CQ}$, closed quotient; $\mathrm{CFx}$, irregularity of frequency; CAx, irregularity of amplitude; F0, fundamental frequency; $\mathrm{NHR}$, noise-to-harmonic ratio; $\mathrm{VHI}$, voice handicap index.

a) $P$-values of less than 0.05 were considered significant.

Table 1. Clinical features of patients with a saccular cyst of the larynx

\begin{tabular}{|c|c|c|c|c|c|c|}
\hline Patient & Age/sex & $\begin{array}{l}\text { Clinical presentation } \\
\text { (MC) }\end{array}$ & $\begin{array}{l}\text { Cyst location/ } \\
\text { growth direction }\end{array}$ & Predisposing factor & $\begin{array}{l}\text { Treatment } \\
\text { strategy }\end{array}$ & Recurrence \\
\hline 1 & 12 mo/Male & Stridor & $\mathrm{Rt} / \mathrm{Ant}$ & Intubation due to RDS & Endoscopic $\mathrm{CO}_{2}$ laser & None \\
\hline 2 & 12 mo/Female & Stridor & Both/Ant & Intubation due to bronchiolitis & Endoscopic $\mathrm{CO}_{2}$ laser & None \\
\hline 3 & $42 \mathrm{yr} /$ Male & Hoarseness & Both/Ant & None & Endoscopic $\mathrm{CO}_{2}$ laser & None \\
\hline 4 & $81 \mathrm{yr} /$ Female & Hoarseness & Lt/Ant & None & Endoscopic $\mathrm{CO}_{2}$ laser & None \\
\hline 5 & $58 \mathrm{yr} /$ Female & Hoarseness & Rt/Ant & None & Endoscopic $\mathrm{CO}_{2}$ laser & None \\
\hline 6 & $32 \mathrm{yr} /$ Female & Hoarseness & Both/Ant & None & Endoscopic $\mathrm{CO}_{2}$ laser & None \\
\hline 7 & $24 \mathrm{yr} /$ Female & FB sense & Lt/Ant & None & Endoscopic $\mathrm{CO}_{2}$ laser & None \\
\hline
\end{tabular}

MC, most common; Rt, right; Ant, anterior; RDS, respiratory distress syndrome; Lt, left; FB, foreign body.

Table 3. The systematic review of published studies on saccular cyst

\begin{tabular}{|c|c|c|c|c|c|c|c|c|c|c|}
\hline Study & Country & $\mathrm{C} / \mathrm{A}$ & $\begin{array}{l}\text { Sample } \\
\text { size }\end{array}$ & Age & $\begin{array}{l}\text { Male: } \\
\text { female }\end{array}$ & MC Sx & Ant:Lat & $\begin{array}{l}\text { Surgery } \\
\text { technique }\end{array}$ & $\begin{array}{l}\text { Follow-up } \\
\text { (mo) }\end{array}$ & Outcome \\
\hline Thabet and Kotob (2001) [7] & $\begin{array}{l}\text { Saudi } \\
\text { Arabia }\end{array}$ & A & 17 & $38.4 \mathrm{yr}$ & $9: 8$ & Dysphonia & All Lat & $\begin{array}{l}\text { Endoscopic, 9; } \\
\text { external app, } 8\end{array}$ & 28.5 & 2 Recurrences \\
\hline Young and Smith (2012) [2] & USA & A & 16 & $52.1 \mathrm{yr}$ & $7: 9$ & Dysphonia & $14: 2$ & $\begin{array}{l}\text { All } \mathrm{CO}_{2} \text { laser- } \\
\text { assisted } \\
\text { microsurgery }\end{array}$ & 11.8 & 2 Recurrences \\
\hline Xiao et al. (2016) [8] & China & C & 28 & $23.9 \mathrm{mo}$ & $13: 15$ & Stridor & $5: 23$ & $\begin{array}{l}\text { All } \mathrm{CO}_{2} \text { laser- } \\
\text { assisted } \\
\text { microsurgery }\end{array}$ & 13 & $\begin{array}{l}\text { No recurrence/ } \\
\text { no complications }\end{array}$ \\
\hline Cohen et al. (2017) [9] & Israel & A & 29 & $60.5 \mathrm{yr}$ & $15: 14$ & Dysphonia & $23: 6$ & $\begin{array}{l}\text { Endoscopic, 24; } \\
\text { external app, 1; } \\
\text { combined app, } 1\end{array}$ & 10 & $\begin{array}{l}\text { 1 Recurrence } \\
\text { associated with } \\
\text { smoking } \\
\text { synchronous } \\
\text { vocal fold disease }\end{array}$ \\
\hline
\end{tabular}

C, congenital; A, acquired; MC, most common; Sx, symptom; Ant, anterior; Lat, lateral; app, approach. 
fore, there would be certain limitations in generalizing the disease characteristics and treatment principles based on this small number of cases. Nevertheless, some saccular cysts could be lifethreatening due to airway obstruction, requiring emergency tracheotomy, particularly in infants and neonates $[8,11,12]$. Additionally, previous studies have reported that carcinoma may be associated with saccular cysts or laryngoceles, with incidences ranging from $5 \%$ to $30 \%$ [4-6]. Considering this possibility of a fatal outcome, we conducted the present study to present an update of the features of this rare laryngeal disease to aid its proper management.

A laryngeal saccule is a blind sac that consists of 50-100 mucous glands, lined with ciliated respiratory epithelium. Its primary function is lubrication of the vocal folds with its secretion [1]. A saccular cyst forms when the opening of this saccule is obstructed due to infection, intubation, or a laryngeal mass [7]. The predisposing factor in both infants in our study was a prolonged intubation history, and considering the funnel-shaped larynx in infants, we speculate that this prolonged period of intubation could have induced obstruction of the saccule opening, which lies in the laryngeal ventricle, leading to development of a saccular cyst [13]. Based on our observation, it is strongly recommended that infants with a prolonged intubation history should be closely followed up.

Differential diagnosis of a laryngeal cyst is often difficult and this may have a marked influence on the treatment strategy. Laryngeal cysts consist of three types, according to its site, content, and status of laryngeal mucosa; ductal cysts, saccular cysts, and thyroid-cartilage foramina cysts [14-16]. The most common type of laryngeal cyst is a ductal cyst. Ductal cysts are caused by retention of mucus in the collecting duct of the submucosal gland. Distinctively, ductal cysts arise from superficial mucosal membrane as a small lesion, mostly less than $1 \mathrm{~cm}$ in diameter and are lined by double-layered epithelium composed of inner columnar and outer cuboidal cells. On the other hand, saccular cysts are dilated saccules that do not communicate with the laryngeal lumen and are generally bigger than ductal cysts. Saccular cysts have a stratified squamous epithelium with a variable number of lymphocytes in their wall. Conversely, laryngoceles communicate with the laryngeal lumen and are air-filled, and it is considered that these develop from long-standing intraluminal pressure. Furthermore, the possibility of an underlying carcinoma should always be considered in the differential diagnosis of saccular cysts [4-6]. The gold standard for diagnosing a saccular cyst is rigid laryngoscopy under general anaesthesia. Magnetic resonance imaging or computed tomography can also provide assistance in confirming the content and extent of the cyst [11].

Saccular cysts can be further classified into two groups according to its growth direction [15]. An anterior-type saccular cyst grows medially and posteriorly between the true and false vocal cords, while a lateral-type cyst grows in a posterosuperior direction between the false vocal cords and aryepiglottic folds.
Particularly, the lateral-type cyst can grow unimpeded through the thyrohyoid membrane, increasing airway compromise. All patients in our series showed anterior-type cysts. However, it is difficult to deduce the incidence of this specific type of cyst due to the small number of patients in this study. Previous reports have reported that the incidence of lateral-type saccular cysts is approximately $30 \%$ [1,12].

Various treatment options have been considered for these lesions, ranging from needle aspiration, endoscopic marsupialization, endoscopic ventriculotomy, to external approaches including a transthyrohyoid membrane approach and laryngofissure, according to the size and growth direction of the saccular cyst. Currently, the standard initial treatment mostly considered for saccular cysts is endoscopic excision $[10,16,17]$. In our series, we achieved complete removal of the cysts in all cases, without recurrence, by using endoscopic $\mathrm{CO}_{2}$ laser excision. More recently, with advancements in the laryngeal endoscopic technique, the larger and lateral-type of saccular cyst can be fully exposed, and $\mathrm{CO}_{2}$ laser provides a precise and hemostatic excisional procedure that avoids rupture of the cystic wall [18]. Using the endoscopic approach, a detailed magnified examination of the saccular cyst is enabled and it is advantageous since it is a minimally invasive approach compared to the open approach which allows patients' quick recovery. However, the endoscopic approach would be relatively difficult in precisely delineating the extent of the larger lesions or relapsed cysts. There is always a chance for these situations in unexpected cases so careful preoperative planning with imaging studies are mandatory. In the present study, only anterior saccular cysts were included but other surgical approaches could be considered in larger, lateraltype saccular cysts.

Voice change is the most common presentation of saccular cysts in adults. Although saccular cysts do not make contact with the true vocal fold, the involved false vocal folds and supraglottic structures are believed to play significant roles in shaping the voice [19]. More specifically, the vocal folds would not be able to adduct completely, due to the cystic mass in the laryngeal ventricle, thereby inducing glottal leakage. Based on the voice analyses of five adult patients with saccular cysts, all endoscopic surgically managed patients showed complete resolution of hoarseness and improved VHI scores, although the changes were not statistically significant.

The primary limitation of this study is the limited number of patients with saccular cysts, which is due to the low incidence of this particular laryngeal pathology. Moreover, only anterior-type saccular cysts were observed, and an endoscopic $\mathrm{CO}_{2}$ laser excision is the sole treatment option in this study. Thus, a comparative analysis with lateral-type cysts and with other treatment options could not be performed. For the following reasons, we performed a systematic review based on previous published studies of saccular cyst (Table 3). Most studies were conducted on relatively small sample sizes and with retrospective designs 
like our study. Thabet and Kotob [7] described their experience with lateral saccular cysts in 2001. They reported that endoscopic excision with $\mathrm{CO}_{2}$ laser is an excellent method for treatment of small and medium-sized lateral saccular cysts of diameter equal to or less than $3 \mathrm{~cm}$. However, surgical excision via an external approach is required for the treatment of huge lateral saccular cysts. With advancements in laryngeal endoscopic technique, most studies performed since 2010 have indicated that endoscopic excision with $\mathrm{CO}_{2}$ laser is a successful and reliable method for anterior and combined saccular cysts $[2,8,9]$.

A saccular cyst is a rare but potentially harmful condition that can lead to airway compromise or malignant transformation. An accurate diagnosis and proper choice of treatment strategy are important to diminish treatment-related morbidity and recurrence. An endoscopic $\mathrm{CO}_{2}$ laser excision is considered appropriate as first-line treatment option for saccular cysts, particularly those of the anterior type. An external approach may be considered as an option for those with extralaryngeal extension or in relapsed cases.

This retrospective case series study has facilitated the characterization of this rare laryngeal condition and has highlighted an appropriate management approach. Nearly all anterior saccular cysts can be managed with great success endoscopically, without the need for an external approach. Therefore, an active endoscopic approach should be considered for optimal treatment outcome.

\section{CONFLICT OF INTEREST}

No potential conflict of interest relevant to this article was reported.

\section{ORCID}

Joo Hyun Kim https://orcid.org/0000-0002-8533-9649 Hyung Kwon Byeon https://orcid.org/0000-0003-3709-2028

\section{REFERENCES}

1. Holinger LD, Barnes DR, Smid LJ, Holinger PH. Laryngocele and saccular cysts. Ann Otol Rhinol Laryngol. 1978 Sep-Oct;87(5 Pt 1): 675-85.

2. Young VN, Smith LJ. Saccular cysts: a current review of characteristics and management. Laryngoscope. 2012 Mar;122(3):595-9.

3. Niparko JK, Moran ML, Baker SR. Laryngeal saccular cyst: an unusual clinical presentation. Otolaryngol Head Neck Surg. 1987 Dec; 97(6):576-9.

4. Harrison DF. Saccular mucocele and laryngeal cancer. Arch Otolaryngol. 1977 Apr;103(4):232-4.

5. Micheau C, Luboinski B, Lanchi P, Cachin Y. Relationship between laryngoceles and laryngeal carcinomas. Laryngoscope. 1978 Apr; 88(4):680-8.

6. Mitroi M, Capitanescu A, Popescu FC, Popescu C, Mogoanta CA, Mitroi G, et al. Laryngocele associated with laryngeal carcinoma. Rom J Morphol Embryol. 2011;52(1):183-5.

7. Thabet MH, Kotob H. Lateral saccular cysts of the larynx: aetiology, diagnosis and management. J Laryngol Otol. 2001 Apr;115(4):293-7.

8. Xiao Y,Wang J, Ma L, Han D. The clinical characteristics of congenital laryngeal saccular cysts. Acta Otolaryngol. 2016;136(2):168-71.

9. Cohen O, Tzelnick S, Galitz YS, Shoffel-Havakuk H, Hain M, Halperin $\mathrm{D}$, et al. Potential causative factors for saccular disorders: association with smoking and other laryngeal pathologies. JVoice. 2017 Sep;31(5):621-7.

10. Hogikyan ND, Bastian RW. Endoscopic CO2 laser excision of large or recurrent laryngeal saccular cysts in adults. Laryngoscope. 1997 Feb;107(2):260-5.

11. Parkes WJ, Propst EJ. Advances in the diagnosis, management, and treatment of neonates with laryngeal disorders. Semin Fetal Neonatal Med. 2016 Aug;21(4):270-6.

12. Civantos FJ, Holinger LD. Laryngoceles and saccular cysts in infants and children. Arch Otolaryngol Head Neck Surg. 1992 Mar;118(3): 296-300.

13. Holzki J, Carroll RG. History of anatomical studies of the pediatric larynx. Paediatr Anaesth. 2016 Feb;26(2):223-5.

14. Kaur A, Kini U, Alva SK. Cysts of the larynx: a clinicopathologic study of nine cases. Indian J Otolaryngol Head Neck Surg. 1998 Jul;50(3):250-6.

15. DeSanto LW, Devine KD, Weiland LH. Cysts of the larynx: classification. Laryngoscope. 1970 Jan;80(1):145-76.

16. Kinnunen I, Klemi P, Grenman R. Saccular laryngeal cysts: three case studies and review of the literature. ORL J Otorhinolaryngol Relat Spec. 2000 Mar-Apr;62(2):109-11.

17. Rubin JS, Silver CE. Surgical approach to submucosal lesions of the supraglottic larynx: the supero-lateral thyrotomy. J Laryngol Otol. 1992 May;106(5):416-9.

18. Kumar S, Garg S, Sahni JK. Radiofrequency ablation of laryngeal saccular cyst in infants: a series of six cases. Int J Pediatr Otorhinolaryngol. 2012 May;76(5):667-9.

19. Zheng X, Bielamowicz S, Luo H, Mittal R. A computational study of the effect of false vocal folds on glottal flow and vocal fold vibration during phonation. Ann Biomed Eng. 2009 Mar;37(3):625-42. 